\title{
PSICOLOGÍA EDUCACIONAL: APORTES PARA EL CAMBIO EDUCATIVO
}

\section{Daniel Trías \& Ariel Cuadro}

\author{
Comentario a cargo de Mag. Daniel Trías \\ Departamento de Psicología del Desarrollo y \\ Educación \\ Facultad de Psicología \\ Universidad Católica del Uruguay
}

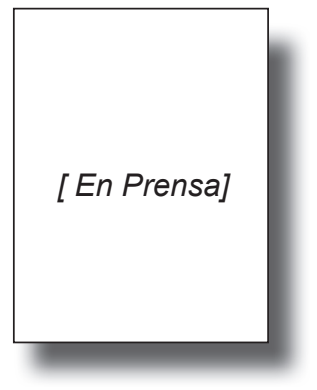

Una larga tradición en Psicología Educacional plantea su centro en los problemas de la realidad educativa, especialmente orientándose al mejoramiento de los procesos de aprendizaje-enseñanza. Sabido es que no existen soluciones mágicas para los problemas que en educación se plantean, pero las contribuciones de la Psicología Educacional pueden, junto con otras disciplinas, aportar al cambio educativo.

En este libro se presenta un grupo de trabajos que abordan distintas temáticas desde la perspectiva educacional y puede ser de utilidad para quienes desean aproximarse a la disciplina de la Psicología Educacional y pensar más a fondo la realidad educativa. En cada capítulo se abordan problemas centrales para el ámbito educativo, se analizan a la luz de un marco teórico contrastado y actualizado, se aportan datos de investigación y se proponen algunas sugerencias de intervención. Los capítulos recogen trabajos realizados por el cuerpo de profesores vinculados al Postgrado y la Maestría en Psicología Educacional, programas de formación que se proponen en la Universidad Católica del Uruguay por más de una década.

Uno de los temas que centrales para la Psicología Educacional es el conocimiento de los procesos de aprendizaje esenciales en el contexto educativo. En ámbitos donde la información se multiplica, contar con recursos estratégicos que permitan seleccionar y jerarquizar contenidos se vuelve cada vez más relevante. Este núcleo se aborda en la primera parte del libro que se titula: "Motivación y habilidades instrumentales". Allí el lector encontrará los siguientes capítulos: "Escenarios que favorecen la autorregulación", "Aprender a leer: una mirada desde la psicolingüística", "La discalculia un poco contado". En conjunto estos capítulos abordan la adquisición de las habilidades instrumentales y claves para el desarrollo de autorregulación.

La segunda parte del libro se titula: "Trastornos del desarrollo y problemáticas sociales en el aula". En conjunto estos capítulos implican pensar sobre algunas situaciones que se dan en el sistema educativo, para atender en mejor medida la diversidad que encontramos en las aulas. Los capítulos que se reúnen en esta parte son: "De los Trastornos del Desarrollo a los Trastornos del Espectro Autista", "Bullying: Asignatura aplazada de la práctica educativa", "Ser madre y estudiar en la adolescencia: Una 'utopía' del contexto educativo uruguayo". 
"Familia, centro educativo y asesoramiento escolar" es el título de la tercera parte del libro. En la misma se reúnen los capítulos que abordan las funciones de asesoramiento y orientación educativa, en distintos niveles del sistema educativo y con distintos actores implicados. Los capítulos que se presentan en esta parte son: "Familia y centros educativos. Caminos para un encuentro", "Desafíos de la educación: el papel de la orientación educativa y vocacional", "Introducción al Counseling Educativo: teoría y práctica".

En conjunto el lector podrá encontrar una diversidad de temas y enfoques, que tienen como finalidad contribuir al mejoramiento de lo educativo. Se ha intentado responder a la realidad nacional, desde una visión actualizada de la Psicología Educacional. El diálogo entre práctica, teoría e investigación es una de las opciones que en el libro se refleja y constituye uno de los caminos a explorar para proponer cambios en lo educativo.

Trías, D. \& Cuadro, A. (2012), (en prensa). Psicología Educacional: Aportes para el cambio educativo. Montevideo: Magró. 